\title{
Translator's Preface
}

Artmachines: Deleuze, Guattari, Simondon contains thirteen essays by French philosopher Anne Sauvagnargues, only two of which have previously appeared in English. Unlike Sauvagnargues's previous collection, Deleuze and Art, published in France in 2005 and in English in 20I3, Artmachines is not a translation of a collection first published in France. This unique collection came about through my fortuitous encounter with Sauvagnargues in Lisbon, at a Deleuze Studies conference and seminar. Listening to Sauvagnargues teach, I realised that her work addressed a philosophical problem I had faced in my own historical research on medieval subjectivity: how do we analyse individuated forms of subjectivity without simultaneously presupposing the existence of an individual, in other words, without presupposing the existence of that which we are purporting to explain? How do we speak of the emergence of any individualised entity as a process, rather than as a fait accompli or as a substance endowed with essence? In a sort of flash of regret coupled with excitement (I had already published my study) I realised that Sauvagnargues was creating the philosophy I needed for the historical questions I was trying to pose. Through a redeployment and transformation of the concepts of Deleuze, Guattari, Simondon, and those of a wide range of other thinkers, Sauvagnargues positions any individuation, human or otherwise, as transitory and as occurring on a plane of actualisation that is always set in relation to a virtual plane of immanence. This has the implication of making us see that any individuation is dynamic, provisional and subject to time and becoming. Perceiving the originality and usefulness of this approach, I expressed as much to Sauvagnargues, along with the offer to translate her work into English to make it more widely available. Within weeks she had sent me at least twenty essays, from which we selected the thirteen contained in the present volume.

Be forewarned. Artmachines begins in medias res. In the three essays 
contained in Part I, 'Individuation on Three Planes: Literature, Philosophy, Art', Sauvagnargues projects us immediately onto the plane of immanence and shows how this repositioning transforms basic assumptions about literature, language, art, history and philosophy. The most immediate effect of this change in position is the falling away of habitual anchors of thought: in literature and art, that of the human author or artist viewed as a genius standing behind a work that in turn is seen to be a representation of reality; in philosophy and history, the assumption that a cause floating above historical and social conditions teleologically orients development; and again in art, the assumption that art exists on a spiritual plane separate from biological and technical modes of production.

In literature (Chapter I), this displacement of perspective to the actual and virtual planes of production changes how we define literary style: no longer the production of an exceptional author whose use of language stands out from usage considered normal or average, style here is defined as a singularity, event, or haecceity emerging on the plane of actualisation (the author's name instead becomes a name for the event, the effect of style). This analysis fulfils the promise of Foucault's 'What is an Author?' to dispense with the notion of the human author as agent and see the author instead as a historicised function of discourse, a position given lip service in American literature departments that still largely organise themselves in terms of great authors, biographical criticism, historical periods and nation-states. Sauvagnargues follows the analysis through: if language itself is always in a state of constant variation and cannot be reduced to an abstract structure or norm, then couldn't any utterance, by any speaker, be classified as an effect of style? A constant theme that recurs in these essays is the rejection of the concept of structure and the presuppositions of structuralism, because these assume that there is an ideal system that can be abstracted from empirical reality. Structuralism adds a transcendent, universalising, or normalising dimension to empirical reality that Deleuze and Guattari always refuse. The concept of structure is replaced by that of the collective assemblage of enunciation or the machine, in which language is embedded in a complex, constantly changing, non-linguistic reality from which no ideal structure can be abstracted.

But, Sauvagnargues asks, if there is no linguistic norm, how do we define style? Can't any speaker then be considered a poet because all language is in a state of perpetual variation? 'Stylistic variation thus comes to be understood as creativity, an intensive placing-into-variation of the stratified forms of language.' While language does not possess an abstract norm or ideal structure, it does have 'stratified forms', that is, as I understand it, 'the way people talk in general', often unbearable because so predictable, so laden with clichés and 'common sense' (as Flaubert still continues to 
teach us). The singularities that now define style affect us because of their strangeness or intensity, a haunting or disturbing quality that distinguishes them from the language we are used to hearing in everyday life, blaring from our technical devices and from people determined to uphold social norms. Sauvagnargues's repetition of Federico García Lorca's haunting line, at five o'clock in the afternoon, with no author's name attached, becomes a talisman that helps us remember that style is a singularity or event of language that produces a mood, an affect, that makes the 'stratified' forms of language tremble and crack.

In Chapter 2, we shift from literature to philosophy. But historians should take note as well: Sauvagnargues emphasises that Deleuze and Guattari's redefinition of philosophy as 'geophilosophy' requires the elaboration of a new model of history to account for the relationship between a philosophy and its social and historical conditions of emergence, one that does not locate philosophy on a superstructure determined by an infrastructure, or that relinquishes philosophy's internal consistency across time. First and foremost, it is necessary to no longer see the activity of philosophy as the search for an already constituted truth, but instead as the encounter between thought and a problem (a view Deleuze derives, as Sauvagnargues shows at various points in Artmachines, from Bergson, Simondon and Proust). It is this encounter between thought and a problem that gives philosophy its relevance, its purchase on historical actuality. In order for thought to encounter a new problem, the problems of our time or of any time, philosophy must be seen to be constructivist: it diagnoses the problem and simultaneously creates a pre-philosophical plane and a conceptual persona that will function as the field of operations and the operator for dealing with the problem. The history of philosophy comes into play here as the collection of concepts that have already been created in past philosophies, that are set to work on a new plane of immanence to address the new problem, and are therefore replayed and reinvented. This redeployment of concepts constitutes the endogenous, virtual consistency of philosophy.

We are thereby led to think about history in a completely different way. In traditional history, a false continuity or causality is imposed upon events that are in actuality contingent and which have the label of inevitability applied to them retroactively. In this sense, Sauvagnargues reminds us that one of the strategies of capitalism has been to impose a universal history upon the past that makes its own contingent emergence appear inevitable. Instead, history consists of the actualisation of virtual possibilities, a view which grants history a necessity that results only from prior contingencies, not from an externally imposed fate or divine will. In my view, a question that emerges from this is, how would rejection of capitalism's universalising 
narrative on the one hand, and the integration of the concepts of actual and virtual on the other, radically change the way we write history, as well as expand our capacity to envision alternate futures?

In Chapter 3, Sauvagnargues redefines art as an 'artmachine', coining the term that gives the present book its title. Of what, precisely, does an artmachine consist? This chapter redefines the image and the sign to thwart our tendency to see both as duplicates of something more real or authentic (and that therefore require interpretation to get to the kernel of truth they contain and conceal) or as projections of the human mind. Instead, both the image and the sign are, on the one hand, considered as instances of real production, and, on the other, as sundered from any human source. They are considered only in relation to other signs and images, situated in 'rhizomes' and 'ecologies' that should be approached through ethology and experimentation rather than through interpretation. Sauvagnargues in part derives this insight from Deleuze's studies of cinema, which drew on both Simondon and Bergson to think the image not in terms of mimesis, but as a process of real individuation occurring within matter (this is addressed in detail in Part II). Equating the image and the sign in that both are singularities or haecceities on a plane of actualisation, Sauvagnargues opens Deleuze's analysis of the cinematic image to Guattari's thought on the sign, semiotics, ritornellos, ecology and ethology. As she does throughout her oeuvre, Sauvagnargues traces an original line between the thought of the two authors, whose close identification ('deleuzeandguattari') often seems to preclude the operation of distinguishing and then reconnecting them. We now think of images as individuations embedded in an ecology of images, always in a state of becoming. In the context of this collection, this chapter can be viewed as a crossroads at which many of the subsequent chapters converge to elaborate an entirely new conception of art. If Deleuze brings together the thought of Bergson and Simondon to elaborate a new philosophy of the image, Sauvagnargues effects a surprising suture between Deleuze and Guattari's individual work (Deleuze on cinema and Guattari on the sign) to create a new concept of the image and of art.

Just as in a Greek tragedy that starts in medias res there is always a 'backstory', or more accurately, significant 'past' events that are virtually present in the actual events unfolding onstage (Medea's theft of the golden fleece for Jason; Antigone's brothers fighting for control of Thebes), in Artmachines, the analyses of individuation and the plane of immanence in Part I are developed in the earlier essays by Sauvagnargues contained in Part II, 'Deleuze: Aesthetics and the Image'. These demonstrate how Simondon and Bergson are decisive for Deleuze's conception of individuation, difference and the plane of immanence (for Simondon, see Chapters 4 and 5; for Bergson see Chapter 5). We can see how Sauvagnargues's concept of 
the artmachine and the ecology of images emerges in part from a rigorous construction of Deleuze's engagement with Simondon on the one hand, and of his work on cinema on the other. Chapter 4 provides a nuanced evaluation of Deleuze's encounter with Simondon's thought, notably the latter's largely uncited but significant contribution to Difference and Repetition with his concept of problematic disparation, which enabled Deleuze to conceive of difference in terms of creation or construction in response to tension between disparate entities in a milieu, rather than difference conceived of in terms of dialectical negation and synthesis. In addition, Simondon's concept of modulation, which dispenses with the explanation of production as the imposition of form upon matter, and instead explains production as a continuous play of forces between entities, powerfully influenced Deleuzian aesthetics and the redefinition of art as a capture of forces and a production of affects and sensations.

In Chapter 5, Sauvagnargues contends with the contributions of both Simondon and Bergson to Deleuze's philosophy of cinema and the invention of the concepts of the movement-image and time-image, both of which are situated on a circuit between virtual and actual planes. If we begin with the virtual plane of immanence defined as a 'universe of universal variation', it is possible for a slowing down or delay to occur (a change in longitude in the play of forces) between an action received and reaction effectuated. In Deleuze's analysis of cinema, this temporal delay is necessary for an individuation to be produced, for actualisation to occur. What occurs during the delay between an action received and the movement effectuated in response? Here, the image, rather than dissipating a perception or an action immediately into a reaction or movement, experiences its own power to affect and be affected (latitude). The image develops a 'sensitive membrane' or a zone of affection and carves out a zone that includes only that which is of interest to it, enacting a sort of 'vital framing'. The image becomes a provisional, transitory centre of determination through the subtraction of all that does not interest it. This is Deleuze's elegant, economic and non-substantial definition of the subject - subjectivity defined as a provisional instance of framing - and an explanation of how perception is derived from movement rather than presupposed to be an aspect of human consciousness. Sauvagnargues calls attention to the fact that the cleavage of perception from human consciousness is facilitated by the technical nature of cinema, which de-anthropomorphises perception by situating it on the plane of matter itself, thereby gaining access to images inaccessible to human perception.

In Part II, Sauvagnargues traces out a line of transformation running through Deleuze's work from the I960s to the I980s, one concerning the transvaluation of the image: from its negative formulation in the 'Image of 
thought' of the I960s, the image is affirmed as an anti-mimetic, impersonal individuation in a state of becoming in the work on cinema in the I980s. In Chapter 6, Sauvagnargues harks back to Deleuze's pejorative definition of the image, in the concept of the Image of thought, in Difference and Repetition, to demonstrate how his work on cinema opened the way for an affirmative treatment of the image in relation to thought. She demonstrates the implications of Deleuze's engagement with cinema for philosophy, opening the possibility for the invention of a new image of thought appropriate to the contemporary (as opposed to the ancient and pre-modern) era. In this new image of thought, Kant's 'table of categories', which presupposes a transcendental, knowing subject, is transformed into a 'table of montage', the framing of a provisional perspective on a plane of immanence through cutting and connecting, the operations proper to montage. Cinema itself supplies us with a new image of thought that is creative rather than reductive, is de-anthropomorphised (not derived from human consciousness), and that is suitable to modern rather than classical conceptions of time, space and motion.

In Part III, 'Schizoanalysis: Territory, Ecology and the Ritornello', Artmachines branches like a medieval romance, following the adventure of another knight, Guattari, in his elaboration of schizoanalysis. Throughout the collection, Sauvagnargues painstakingly untangles the thought of Guattari from that of Deleuze, in turn revealing previously unspecified points of connection and collusion. She shows us how with Guattari we are in the midst of a drawn-out battle, one with an opponent who is familiar and who, in certain circumstances, is not an opponent at all, but rather an interlocutor who relies upon concepts nevertheless deemed transcendent and universalising: namely, Lacan and his linguistic model of the unconscious. For Guattari, while this model, by insisting upon its linguistic structure, has the merit of conceptualising the unconscious in terms of the social field rather than a personal individual, it merely trades one universal (Freud's Oedipus complex) for another (the phallus and castration), both of which he claims obscure the productive, machinic nature of the unconscious. Even worse, the definition of the unconscious in terms of structural linguistics excludes non-linguistic components and historical actuality. I would add here that in my years teaching Lacanian theory at an American art school, the greatest resistance my students express to Lacan concerns this insistence upon the absolute centrality of language to the unconscious. How can this be so, in our era, which is witnessing the waning of the printed word and in which the image and visual media dominate?

Guattari shifts the focus of psychoanalysis away from interpretation toward experimentation, and his concept of the 'ritornello', the focus of Chapter 7 , in effect explains how all creatures, not just humans, change 
through experimentation, through an alternation between territorialisation and deterritorialisation. As part of the shift away from an anthropomorphic perspective, Sauvagnargues demonstrates how both Deleuze and Guattari deploy modes of thought (e.g., ethology and the Markov chain) that eradicate differences between the human, biological and technical levels of existence. All living beings strive to configure a territory through the arrangement and consolidation of expressive signs, both linguistic and non-linguistic (the child whistling in the dark, the bird configuring its territory). Presenting a new, ethological version of individuation, the ritornello refers to a procedure of vital framing or a provisional centring through the repetition of signs and habits in response to a situation that has become too chaotic to bear (the child whistling in the dark to ward off fear, to create a provisional centre), recalling Deleuze's definition of the subject as a provisional centring on the plane of actualisation (Part II). Thinking existence in terms of the ritornello offers an appealing alternative to Freudian psychoanalysis, which importantly focuses on the symptom and the repressed traumas it condenses, but which remains vague on the question of how to creatively deploy repetition and the symptom to create a different future (I would add that in the I970s, with the conceptualisation of the 'sinthome', Lacan presents the work of the symptom as a creative process - Joyce's experiments with language being a privileged example - but he maintains the triad of the Real-Symbolic-Imaginary, inherently problematic to Guattari).

Chapter 9 deals specifically with the need to rethink the symptom in light of Guattari's work: 'We should not translate the symptom as a map of the past in accordance with the reductionist modelling of psychoanalysis, but instead make use of it to experiment with becomings, to explore cartographies of a possible future.' Like style, like the philosophical concept, and like the image, the symptom is situated on a circuit between actual and virtual planes. Seen in this way, the symptom is treated affirmatively, standing for the possibility of becoming or a change in actual circumstances, rather than as an indicator of a personal, repressed trauma to be deciphered and neutralised through interpretation. Like the ritornello, the symptom that becomes actualised may or may not gain consistency and create lasting change; it instead offers a site for experimentation: 'The symptom is always plural and as such it is assemblage, a kinetic fragment, a point of view that opens the way to a reconfiguration of territory.' Two key points of disagreement Guattari has with Freudian and Lacanian psychoanalysis, then, concern not whether the symptom is important, but, on the one hand, what to do with it (to experiment with it or to interpret it), and on the other, to whom it refers (a collective unconscious complex open to historical actuality or a personal unconscious formed within the confines of the Oedipal complex). 
A pitched battle between Lacan and Guattari, between the master and his old student, takes place at the site of the signifier. Lacan himself broke away from his master, Freud, through his original work on psychosis. Already enacting his return to Freud through the introduction of structural linguistics on the plane of Freudian thought in his work with psychotics, Lacan made the important discovery that the distinction between the neurotic and the psychotic occurs at the level of the structure of the unconscious, and concerns the foreclosure of the paternal function, the name Lacan gives to the transcendent entity, the 'quilting point', that confers meaning upon the signifying chain (Chapter 8). Diagnosing the transcendent character of this concept, as well as the idealisation that always accompanies structure, Guattari replaced Lacan's paternal function as the organiser of discourse and meaning with the desiring machine. While, like Lacan, he accepted that the unconscious undergoes a process of coding, he proposed a mode of coding that was not exclusively linguistic and that took historical actuality into account. This marked Guattari's important shift from the concept of structure to that of the machine, in this case the conception of the unconscious as a desiring machine, predicated upon connectivity and production and not bounded by individual or familial boundaries or representations.

I felt it important to include Chapter ro in Artmachines to supplement the scant material available in English about Fernand Deligny, whose life's work addressed the controversial topics of childhood and autism. Deligny's collective works have only recently been published in France (in 2007 and 2008), and, as the essay points out, he eludes easy disciplinary categorisation, the labels writer, artist, therapist, filmmaker and philosopher all resonating while remaining insufficient. Sauvagnargues navigates his massive and diverse oeuvre to extract a perspective that gives us an orientation point, one concerning Deligny's resistance to definitions of the human in terms of language. For Deligny, the human needs to be defined in terms of ethology, not linguistics. One problem with language, with its subjectpredicate structure, is that it creates the illusion of human will or intention and of notions of cause and effect (here, Deligny follows Spinoza). His work also recalls Foucault's insight that knowledge is a relay of power (in this case, the production of the abstract child as an object of knowledge). Deligny's concept of the arachnéen (the French term that denotes 'spiderlike qualities') involves an 'ecological competence' and a strategic mode of operating that resists established institutions, experimenting with existing elements in the surrounding milieu, thereby recalling Guattari's concept of transversality. The arachnéen takes advantage of what it finds at hand and of its ability to insinuate itself in the nooks and crannies of institutions, just as a spider spins its transitory web wherever conditions are available 
and advantageous. The focus is on experimentation and chance in a lived milieu, evoking a kind of chaosmic submersion into the virtual cloud and the retrieval of a differentiated complexion, recalling Guattari's concept of the symptom (Chapter 9). Sauvagnargues implicitly shows us how Deligny's experiments embody some of Deleuze and Guattari's key concepts - cartography, lines of flight, territory - in a startlingly tactile way.

An insistent 'ritornello' in this book is the replacement of the concept of structure with that of the machine, which is the focus of Part IV, 'Machines and Assemblages'. Structure always drags along with it the notion that any real thing is doubled by an ideal or normative model, whereas the machine, whose definition is expanded far beyond our common-sense 'mechanical' definition, offers a purely immanent and open concept for analysing complex social realities, including all manner of heterogeneous elements including language, non-linguistic signs, images, technology, desire and the unconscious, without resorting to ideals or normative structures. The machine encompasses not just the isolated technical object, but also its entire milieu of individuation, which functions as a 'transcendental milieu of possibility' (Chapters II and I2). The unconscious and desire are coded under these real conditions, not in terms of Oedipus or the family. Marx and Freud are brought together in unique way, opening the unconscious and desire directly to real social conditions, including the organisation of production, labour, surplus value and language (the collective assemblage of enunciation) that gives a social assemblage its consistency. As in the economic definition of subjectivity as provisional framing or centring on the plane of immanence, here, subjectivity is peripheral, adjacent to the components of the social machine.

The components of the machine are held together not by any transcendent glue, but by an 'abstract machine', the virtual cloud that accompanies any social machine and becomes palpable only at the points where the machine breaks down. Again, we are reminded of the importance of situating any analysis in relation to the actual and virtual planes. The abstract machine, which introduces the possibility of becoming into any social machine (Kafka diagrams these virtual possibilities in his novels), is closely related to the Foucauldian diagram (Chapter I2), which calls for an analysis that reveals the relations of forces that constitute the regimes of power, knowledge and social visibility. 'Preferential nodes of forces' are given the name 'strata' (Chapter I3). Strata 'lock singularities' and oppose vital becoming. In the history of the West, with the emergence of Christianity and capitalism, two strata intersected by chance in a particular way: the strata of significance and of subjectification, making possible the emergence of the abstract machine of faciality, the virtual conditions for the possibility of the face, no longer considered a natural component of the 
human body. Rather, the face is a molar stratification that is traversed by molecular, deterritorialising forces that offer subjectivity in the West the chance to become something else, something other than the oppressive, colonising, great White Man. Here, Sauvagnargues brilliantly aligns the difficult concept of the abstract machine with Foucault's notion of diagram (via Deleuze's reading of Foucault), supplying us with a crucial way of speaking of immanent causality in history, at the same time as she demonstrates how Ruyer's presentation of the Markov chain offered Deleuze and Guattari a means of dispensing with the notion of structure and signification once and for all, instead viewing language as 'jargon' characterised by a collusion between chance and localised determinism.

Sauvagnargues's writing style in French possesses a fluidity, dynamism and elegance that I cannot hope to have fully captured in the translation. At the same time, despite their sophistication, the rigour, logic and clarity of her arguments made the task of translation much easier, a kind of intellectual adventure. In translating these essays, I consulted the English translations of the works to which they refer, and mostly retained the commonest translations of new words and concepts. For example, I have kept the English 'assemblage' for the French 'agencement', even though the French term conveys a sense of action and dynamism than the English 'assemblage' lacks, conveying more of a sense of static heterogeneity without movement. Often, but not always, I translate 'sens' as 'sense' rather than meaning, to recall the status of 'sense' as an event rather than an essential kernel hiding below the surface. A major exception is the French term 'ritornelle', which was translated into English as 'refrain' in A Thousand Plateaus, but which I have decided to render as 'ritornello'. I did so because we have a similar word in English, even if it is less familiar. To me, 'refrain' in English has a negative connotation, suggesting dull repetition, whereas 'ritornello' has the affirmative connotation of repetition coupled with transformation and creativity, repetition that offers the possibility of drawing a line of flight, a way out. In addition, the nasal sound of the second syllable of 'refrain' connotes a kind of droning or grinding, whereas the open vowels of 'ritornello' connote openness and possibility.

I am indebted to Eugene Holland for offering his expertise to this project by scrutinising every word of the first draft, making invaluable corrections, polishing rough edges, and supplying more apt phrasings. Any errors that remain are mine, not his. I am also indebted to Gregory Flaxman, who - in addition to writing the introduction, putting Sauvagnargues's work in the context of both her oeuvre and the state of contemporary philosophy - offered advice on the translation of terms and the organisation of the essays. Peter Canning provided a crucial critique of this preface. I am also grateful to Carol Macdonald at Edinburgh University Press for her 
confidence in this project from its inception, and her patience and attention throughout the process.

Finally, Sauvagnargues requested that I to try to avoid words or phrases that promote the fiction of substance or essence. This was my intention, but I will leave it to the reader to judge whether I succeeded. It is important for the reader to know, though, that this was my intention and the author's wish.

Suzanne Verderber 
